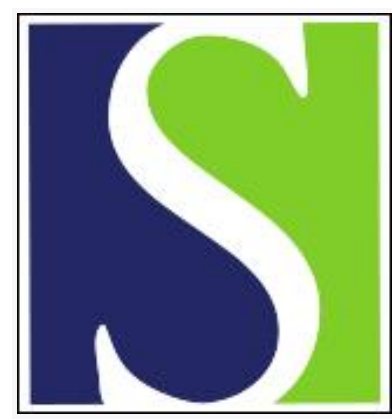

Scand J Work Environ Health 1982;8(4):283-289

https://doi.org/10.5271/sjweh.2465

Issue date: Dec 1982

Nasal histology and nickel concentration in plasma and urine after improvements in the work environment at a nickel refinery in Norway.

by Boysen M, Solberg LA, Andersen I, Hogetveit AC, Torjussen W

This article in PubMed: www.ncbi.nlm.nih.gov/pubmed/7170625

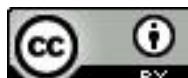




\title{
Nasal histology and nickel concentration in plasma and urine after improvements in the work environment at a nickel refinery in Norway
}

\author{
by Morten Boysen, ${ }^{1}$ Lars A Solberg, ${ }^{2}$ Ivar Andersen, ${ }^{3}$ Arne C Høgetveit, ${ }^{3}$ \\ William Torjussen ${ }^{4}$
}

\begin{abstract}
BOYSEN M, SOLBERG LA, ANDERSEN I, HOGETVEIT, TORJUSSEN W. Nasal histology and nickel concentration in plasma and urine after improvements in the work environment at a nickel refinery in Norway. Scand $j$ work environ health 8 (1982) 283289. Nasal histology and nickel concentration in the plasma and urine of nickel workers were reexamined after 4 a for an evaluation of the effect of improvements in the refining process and work conditions. Ninety-eight $(31 \%)$ nickel workers who were part of a previous study were reexamined. In addition, 33 of the original 38 workers with nasal epithelial dysplasia were studied for possible regression of the histological changes. Reduction in the atmospheric content of nickel and improved hygienic conditions lowered the concentration of nickel in plasma and urine by approximately $50 \%$. The mean histological score and frequency of dysplasia was virtually the same in the two investigations, 12 and $13 \%$, respectively. Nasal biopsies are of limited diagnostic value in the examination of individual cases. However, the method seems to be of value in identifying and monitoring groups of persons with increased risk of developing nasal carcinoma.
\end{abstract}

Key terms: nasal mucosa changes, nickel workers.

The inhalation of nickel compounds is associated with an increased incidence of carcinomas of the respiratory tract, particularly of the nasal cavities $(6,7,11,13)$. A recent study of the nasal mucosa of process workers in a Norwegian nickel refinery revealed epithelial dysplasia in $12 \%$ and carcinoma in $0.6 \%$ of the workers (18). The nickel content in the plasma and urine of these workers was considerably

1 Department of Pathology, Norsk Hydro's Institute for Cancer Research, The Norwegian Radium Hospital, Oslo, Norway.

2 Department of Pathology, Ullevål Hospital, Oslo, Norway.

3 Falconbridge Nikkelverk A/S, Kristiansand, Norway.

4 Department of Otorhinolaryngology, Central Hospital, Kristansand, Norway.

Reprint requests to: Dr M Boysen, Laboratory for Electron Microscopy and Morphometry, Department of Pathology, Norsk Hydro's Institute for Cancer Research, The Norwegian Radium Hospital, Montebello, Oslo 3, Norway. higher than in nonexposed persons (16). The high frequency of respiratory tract carcinomas and nasal epithelial dysplasia led to measures to reduce the amount of nickel in the refinery environment. A preventive health program was also introduced, part of which was to monitor the content of nickel in the plasma and urine of the workers and, if possible, to detect respiratory tract malignancies $(8,9)$.

The present study is based on the reexamination of $31 \%$ of the nickel workers first examined in 1976 (18). Our purpose was to evaluate (i) whether the improvements introduced in the refining process had reduced the amount of nickel in the environment, (ii) whether the technical improvements and improved hygienic conditions had reduced the nickel content in the workers' plasma and urine, and (iii) whether the same improvements had resulted in the regression of histological changes in the workers' nasal mucosa. 


\section{Material and methods}

The raw material refined at Falconbridge Nikkelverk A/S, Kristiansand, Norway, is nickel matte containing $50 \%$ nickel, $30 \%$ copper, $20 \%$ sulfur, and trace amounts of other metals. The nickel is processed by crushing, roasting, smelting, and electrolysis.

Workers involved in the roasting/smelting process are mainly exposed to dry furnace dust of water-insoluble nickel subsulfide and oxide. In the electrolysis department workers are mainly exposed to water-soluble aerosols of nickel sulfate and chloride. Nonprocess workers include plumbers, fitters, and electricians doing maintenance work in these two departments, as well as workers employed in other departments of the plant. These workers are exposed to various nickel compounds, but generally at lower concentrations and for shorter periods than the first two groups of workers.

Since 1976 several improvements have been introduced in order to reduce the amount of nickel in the atmosphere. The main technical improvements include the replacement of the old Hereshof roasters by fluid bed furnaces, the covering of the electrolysis tanks with expanded polystyrene pellets, and the installation of new fans.

\section{Follow-up of previously examined nickel workers}

Two groups of workers were selected for reexamination in the period 1979-1981. The protocol of the original examination (18) was followed.

Group I comprised 98 (31\%) randomly selected workers (table 1) of the $318 \mathrm{ex}$ - amined in 1976. All volunteered for the reexamination. Ten workers had changed jobs since 1976 . Of these, seven are virtually nonexposed to nickel in their present jobs, but three are still exposed as process workers (see footnote a of table 3 ).

In order to follow the course of nasal epithelial dysplasia, we wished to reexamine as many of the workers as possible in whom dysplasia was diagnosed in 1976. Of these 38 workers, 33 were reexamined after approximately $2.5 \mathrm{a}$, and 16 were also examined after approximately 4.5 a. These 33 reexamined workers formed group II; 12 of them are also included in group I.

\section{Reference group}

Samples of blood and urine were collected from 20 age-matched volunteers from the office staff of the refinery for comparison with the blood and urine of the refinery workers.

\section{Collection of samples}

Biopsies were taken under local anesthesia (Xylocain $2 \% /$ Adrenalin $0.1 \%$ ) from the anterior curvature of the middle turbinate on the same side as in the original examination. The specimens were fixed in cacodylate-buffered $3 \%$ glutaraldehyde $(\mathrm{pH}$ 7.4), embedded in Epon, sectioned $(1 \mu \mathrm{m})$, and stained with toluidine blue.

Blood and urine were collected the first thing in the morning, at least $12 \mathrm{~h}$ after work, and on the same day as the biopsy specimens. The nickel concentration was determined by an atomic absorption spectrophotometer (model 603) equipped with a graphite furnace (model HGA-76, auto

Table 1. Age and the duration of nickel exposure of the active nickel workers (allocated according to category of work) and the referents.

\begin{tabular}{|c|c|c|c|c|c|}
\hline & \multirow{2}{*}{$\begin{array}{c}\text { Number of } \\
\text { subjects }\end{array}$} & \multicolumn{2}{|c|}{ Age (a) } & \multicolumn{2}{|c|}{ Employment (a) } \\
\hline & & Mean & Range & Mean & Range \\
\hline \multicolumn{6}{|l|}{ Exposed subjects } \\
\hline $\begin{array}{l}\text { Roasting/smelting } \\
\text { Electrolysis } \\
\text { Nonprocess }\end{array}$ & $\begin{array}{l}29 \\
41 \\
28\end{array}$ & $\begin{array}{l}50 \\
54 \\
53\end{array}$ & $\begin{array}{l}37-64 \\
32-64 \\
37-67\end{array}$ & $\begin{array}{l}22 \\
25 \\
24\end{array}$ & $\begin{array}{l}12-30 \\
12-34 \\
14-34\end{array}$ \\
\hline All nickel workers & 98 & 52 & $32-67$ & 24 & $12-34$ \\
\hline Referents & 20 & 52 & $42-73$ & & \\
\hline
\end{tabular}


sampling system, AS-1) and a model 56 recorder, both from the Perkin-Elmer Corp, Norwalk, CT, USA, as previously described by Torjussen \& Andersen (16).

The safety engineer collected air samples by using static samplers at fixed places in the work areas. The air samples were analyzed with the same equipment as the plasma and urine samples.

\section{Histological examination}

The biopsy specimens were histologically graded according to a classification scale slightly modified from Torjussen et al (17, 18) (see table 2). All sections from the original and present examination were examined independently by two of the authors (MB \& LAS), who did not consult the previous histological descriptions or clinical/occupational information. In a few

Table 2. Histological classification of nasal surface epithelium. The sections were given the highest score obtained according to presence of one of the listed characteristics.

\section{Characteristic}

Score

Pseudostratified columnar epithelium

Stratified cuboidal epithelium

Mixed stratified cuboidal/stratified

squamous epithelium

Stratified squamous, nonkeratinizing

epithelium

Stratified squamous, keratinizing epithelium

Dysplasia

2

cases of disagreement, a concensus was reached after some discussion.

\section{Statistical evaluation}

The Wilcoxon test for paired differences was used to compare the 1976 histological scores and the nickel levels in plasma and urine with those of the present study. The Wilcoxon test for two samples was used to compare the nickel values of the exposed workers and the referents. To compare the frequency of dysplasia in 1978/ 1979 and 1980/1981, the square contingency test was ápplied. A probability level of less than $5 \%$ was required for significance.

\section{Results}

\section{Atmospheric nickel concentrations}

In 1976 the atmospheric nickel concentration ranged from 0.1 to $1.0 \mathrm{mg} / \mathrm{m}^{3}$ in the roasting/smelting department and from 0.1 to $0.5 \mathrm{mg} / \mathrm{m}^{3}$ in the electrolysis department. The nonprocess workers were exposed to levels ranging from 0.01 to 0.5 $\mathrm{mg} / \mathrm{m}^{3}$.

Repeated analyses of atmospheric nickel in the new smelting department and in the electrolysis department in 1979-1980 revealed values of less than $0.1 \mathrm{mg} / \mathrm{m}^{3}$.

3 Nickel analysis in plasma and urine

Fig 1 presents the results of the nickel analyses of the plasma and urine of the 98
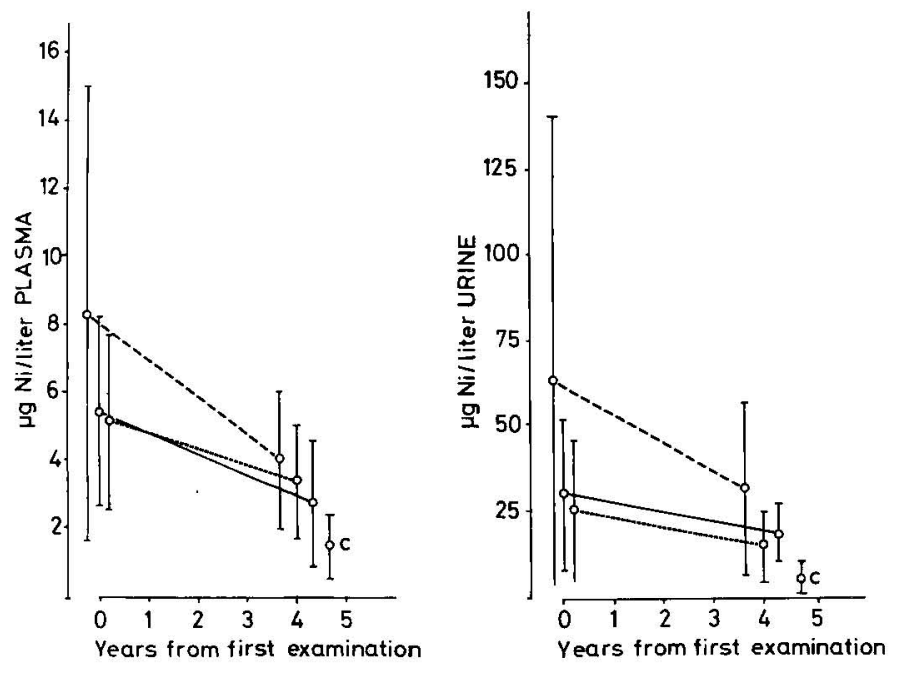

Fig 1. Nickel levels in the plasma and urine of the 98 nickel workers examined in 1976 and 1979/1980 (mean + SD). For all categories of work the 1979/ 1980 values were significantly lower than the 1976 ones $(p<0.05)$, but they still exceeded those of the referents (c) $(p<0.05) \quad(---: \quad$ workers in the electrolysis department, workers in the roasting/smelting department, $\cdots$ nonprocess workers) $(1 \mu \mathrm{g} \mathrm{Ni} / \mathrm{l}$ plasma $=0.017$
$\mu \mathrm{mol} / \mathrm{l})$. 
workers in group I in the present and former study. The mean plasma and urine nickel values for all categories of workers were reduced by approximately $50 \%$ $(p<0.05)$, but they still exceeded the values recorded for the referents who had minimal exposure to nickel $(\mathrm{p}<0.05)$.

The 33 workers with epithelial dysplasia in 1976 (group II) also showed a significant decrease in their plasma and urine nickel concentrations $(p<0.05$ ) (fig 2 ). Only the plasma and urine values of the electrolysis workers and the urine values of the roasting/smelting workers exceeded the values recorded for the referents $(p<0.05)$. The apparent increase in the nickel values of the roasting/smelting workers after $4.5 \mathrm{a}$ is probably due to the limited number of observations.

\section{Histological examination}

Table 3 summarizes the results of the histological examination of group I. The mean histological score and the percentage of individuals with epithelial dysplasia were virtually identical in 1976 and $1979 / 1980$, namely, 12 and $13 \%$, respectively. The comparison of the examinations presented in table 4 shows that 30 workers $(30.6 \%)$ obtained the same score, $38(38.8 \%)$ a lower, and $30(30.6 \%)$ a higher score in

Table 3. Histological scores of the 98 active nickel workers examined in 1976 and 1979/1980.

\begin{tabular}{|c|c|c|c|c|c|c|c|c|}
\hline \multirow{2}{*}{$\begin{array}{l}\text { Category of } \\
\text { work }\end{array}$} & \multirow{2}{*}{$\begin{array}{l}\text { Number of } \\
\text { workers }^{a}\end{array}$} & \multicolumn{7}{|c|}{ Histological scoreb } \\
\hline & & 0 & 1 & 2 & 3 & 4 & 5 & Mean \\
\hline \multicolumn{9}{|l|}{ Examination in 1976} \\
\hline $\begin{array}{l}\text { Roasting/smelting } \\
\text { Electrolysis } \\
\text { Nonprocess }\end{array}$ & $\begin{array}{l}34 \\
43 \\
21\end{array}$ & $\begin{array}{l}0 \\
0 \\
0\end{array}$ & $\begin{array}{r}10 \\
8 \\
8\end{array}$ & $\begin{array}{r}5 \\
11 \\
8\end{array}$ & $\begin{array}{r}7 \\
11 \\
1\end{array}$ & $\begin{array}{l}8 \\
8 \\
1\end{array}$ & $\begin{array}{l}4 \\
5 \\
3\end{array}$ & $\begin{array}{l}2.74 \\
2.79 \\
2.19\end{array}$ \\
\hline \multicolumn{8}{|c|}{ Examination in $1979 / 1980$} & 2.64 \\
\hline $\begin{array}{l}\text { Roasting/smelting } \\
\text { Electrolysis } \\
\text { Nonprocess }\end{array}$ & $\begin{array}{l}29 \\
41 \\
28\end{array}$ & $\begin{array}{l}1 \\
1 \\
2\end{array}$ & $\begin{array}{l}2 \\
2 \\
6\end{array}$ & $\begin{array}{l}7 \\
7 \\
7\end{array}$ & $\begin{array}{r}12 \\
12 \\
7\end{array}$ & $\begin{array}{l}2 \\
2 \\
2\end{array}$ & $\begin{array}{l}5 \\
5 \\
4\end{array}$ & $\begin{array}{l}2.90 \\
2.55 \\
2.54\end{array}$ \\
\hline All nickel workers & 98 & 4 & 17 & 22 & 34 & 8 & 13 & 2.65 \\
\hline
\end{tabular}

a Five workers employed in the electrolysis department and two in the roasting/smelting department in 1976 were employed as nonprocess workers at the time of the 1979/1980 examination. Three workers employed in the roasting/smelting department in 1976 were working in the electrolysis department in 1979/1980.

b The changes in the histological scores are not statistically significant.
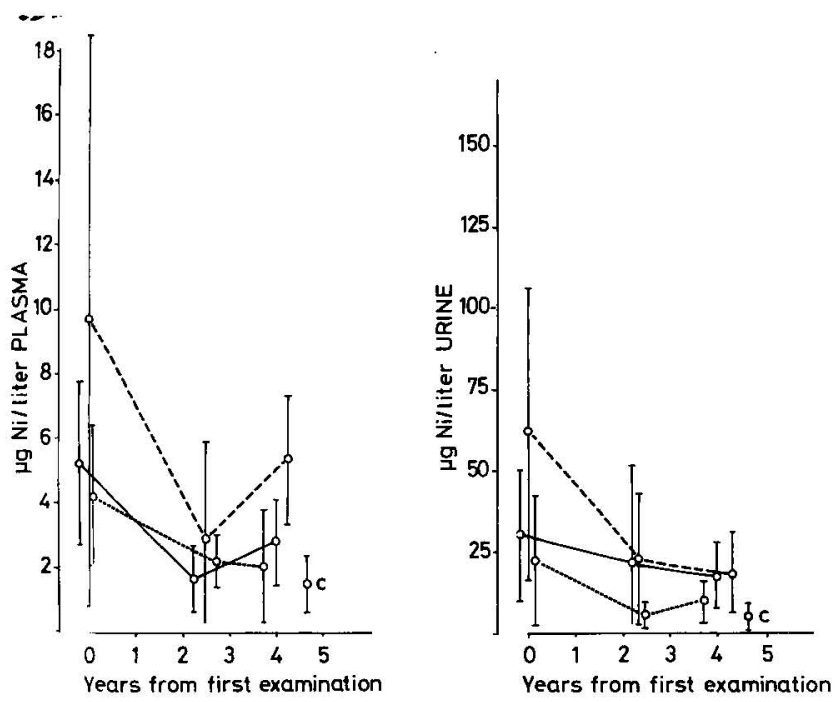

Fig 2. Nickel levels in the plasma and urine of the 33 nickel workers with nasal epithelial dysplasia in 1976, reexamined after 2.5 and 4.5 a (mean + SD). For all categories of work the values recorded in the follow-up examination were significantly lower than the 1976 ones $(p<0.05)$. Only the urine values of the workers in the electrolysis and the roasting/ smelting department and the plasma values of workers in the former differed significantly from those of the referents (c). For symbols see fig 1. (1 $\mu \mathrm{g} \mathrm{Ni} / \mathrm{l}$ urine $=0.017 \mu \mathrm{mol} / \mathrm{I}$ ). 
the latest examination ( $p>0.05)$. Only for $20 \%$ did the score differ by more than one when the two examinations were compared. Of the 12 workers with dysplasia in 1976 , only six showed dysplasia when rebiopsied in 1979/1980 (table 4), but dysplasia was now found in seven other workers.

The results of the reexamination of workers with dysplasia in 1976 (group II) are presented in table 5 . Of the 33 workers rebiopsied after $2.5 \mathrm{a}$ and the 16 workers examined after 4.5 a, $13(39 \%)$ and $8(50 \%)$, respectively, showed dysplasia. No case of carcinoma was found in the present investigation.

\section{Discussion}

Occupational exposure to nickel is associated with an increased risk of respiratory tract carcinoma (10). For workers who, in the period 1953-1971, were involved for 3 a or more in roasting/smelting and electrolysis work at Falconbridge Nikkelwerk, Kristiansand, Norway, the ratio of observed to expected cases of nasal carcinoma was $40: 1$ and the corresponding ratio for lung carcinoma was $7: 1$ (13). For nasal carcinoma the ratio increased with the duration of employment, being $168: 1$ for workers employed for 25 a or more (1). The nonprocess workers showed approximately three times the incidence of respiratory carcinoma when compared to nonexposed individuals (13). Although other chemical compounds such as copper, cobalt, arsenic, and sulfur may be of importance, it is nickel compounds, especially the water-insoluble ones, which are considered to be the main carcinogenic substances $(14,15)$.

In order to reduce the amount of airborne nickel in the refinery, during the last few years there has been a changeover from an open metallurgical to a closed chemical production process. This change has resulted in the airborne content of nickel being reduced to values below the hygienic standard of $0.1 \mathrm{mg} / \mathrm{m}^{3}$, the value recommended by Norwegian authorities for occupational exposure to nickel. At the same time an extensive health program has been introduced including, among other tests, an annual medical examination, chest radiographs, and regular measurement of the nickel content in plasma and urine. Workers with a high body burden of nickel are instructed in hygienic pre-

Table 4. Histological score of the 98 active nickel workers examined in 1976 and 1979/1980.

\begin{tabular}{lccccccc}
\hline \multirow{2}{*}{$\begin{array}{l}\text { Histological } \\
\text { score in } \\
1979 / 1980\end{array}$} & 0 & 1 & 2 & 3 & 4 & 5 & Total \\
\cline { 2 - 6 } & 0 & 3 & 0 & 1 & 0 & 0 & \\
\hline 0 & 0 & 6 & 7 & 1 & 2 & 1 & 4 \\
1 & 0 & 4 & 7 & 8 & 1 & 2 & 17 \\
2 & 0 & 9 & 8 & 6 & 9 & 2 & 34 \\
3 & 0 & 0 & 0 & 2 & 5 & 1 & 8 \\
4 & 0 & 4 & 2 & 1 & 0 & 6 & 13 \\
5 & 0 & 26 & 24 & 19 & 17 & 12 & 98 \\
\hline Total & & & &
\end{tabular}

Table 5. Histological score of 33 and 16 nickel workers presenting nasal epithelial dysplasia in 1976 after 2.5 and 4.5 a, respectively.

\begin{tabular}{|c|c|c|c|c|c|c|c|c|}
\hline \multirow{2}{*}{$\begin{array}{l}\text { Category of } \\
\text { work }\end{array}$} & \multirow{2}{*}{$\begin{array}{l}\text { Number of } \\
\text { workers }\end{array}$} & \multicolumn{7}{|c|}{ Histological score $^{a}$} \\
\hline & & 0 & 1 & 2 & 3 & 4 & 5 & Mean \\
\hline \multicolumn{9}{|c|}{ Examination in $1978 / 1979$} \\
\hline Roasting/smelting & 11 & 0 & 2 & 0 & 3 & 2 & 4 & 3.55 \\
\hline Electrolysis & 13 & 0 & 1 & 2 & 6 & 0 & 4 & 3.31 \\
\hline Nonprocess & 9 & 0 & 2 & 1 & 1 & 0 & 5 & 3.56 \\
\hline All nickel workers & 33 & 0 & 5 & 3 & 10 & 2 & 13 & 3.45 \\
\hline \multicolumn{9}{|c|}{ Examination in $1979 / 1980$} \\
\hline Roasting/smelting & 3 & 0 & 0 & 0 & 1 & 0 & 2 & 4.33 \\
\hline Electrolysis & 6 & 0 & 1 & 1 & 2 & 0 & 2 & 3.16 \\
\hline Nonprocess & 7 & 0 & 0 & 2 & 0 & 1 & 4 & 4.00 \\
\hline All nickel workers & 16 & 0 & 1 & 3 & 3 & 1 & 8 & 3.75 \\
\hline
\end{tabular}

a The changes in the histological scores are not statistically significant. 
cautions, in irrigation of the nasal cavities with $0.9 \%$ saline after work, and in the wearing of protective masks. Reduced work time has been instituted in some of the areas where a high level of nickel was registered (8).

The most generally accepted and widely used method for monitoring occupational nickel exposure is the determination of nickel in blood and urine $(2,9,12)$. The present study shows that the reduction in airborne nickel and improvements in hygiene have resulted in a significant reduction in plasma and urine nickel concentrations during the years from 1976 to 1979 / 1980 , but the level of nickel in the plasma and urine of the nickel workers is still somewhat higher than in referents. Whether this phenomenon is related to the amount of nickel still present in the occupational atmosphere or due to the slow release of nickel accumulated within the organism during previous higher exposure is difficult to decide.

The real significance of nasal epithelial dysplasia is not known at present. The fact that such lesions are found within occupational groups with an increased incidence of nasal carcinoma, eg, among nickel (17, 18 ) and furniture (5) workers, strongly suggests that dysplasia should be considered a precancerous lesion. This probably close relation between dysplasia and carcinoma is also illustrated by our experience of a nasal carcinoma developing in a retired nickel worker $2 \mathrm{a}$ after dysplasia was found in the same nasal cavity.

Despite individual variation, we found that the mean histological score and the frequency of dysplasia remained virtually the same in our 98 workers after 4 a of observation. This result suggests that once established, dysplasia shows little tendency towards regression. The high frequency of dysplasia among retired nickel workers supports this assumption (17, Boysen et al, unpublished results). The possibility that even the present low atmospheric nickel contamination is sufficient to maintain, in principle, reversible dysplasia cannot be completely excluded. Neither can it definitely be ruled out that nickel accumulated in the nasal mucosa continues to influence the epithelium adversely. However, within a span of $4 \mathrm{a}$ and after substantial improvements in the individual nickel load, one would expect reac- tive epithelial changes to subside. In our opinion the constant prevalence of dysplasia among the nickel workers studied favors the view that these morphological changes express early and essentially irreversible steps in a gradual malignant transformation of the nasal epithelium.

Dysplasia appears in scattered areas in the nasal mucosa $(3,4)$. Due to the limited size of the biopsies such areas may easily be missed, and therefore some of the workers who showed dysplasia in the first biopsy failed to do so when rebiopsied and, also, a number of "new" cases of dysplasia were found in the present investigation.

On the basis of the findings in the present and previous (18) studies attempts were made to evaluate the real prevalence of nasal epithelial dysplasia, and whether regression or progression of dysplasia takes place. The application of static and dynamic statistical models suggests that a moderate increase in the frequency of dysplasia is likely and that substantial regression or progression can be excluded. The real prevalence of dysplasia in active nickel workers is at least twice the percentage detected in single studies. Depending on the model used, the mean values varied between 58 and $27 \%$, with a lower end of the $95 \%$ confidence interval at 24-16\%. Moreover, the statistical evaluation shows that at least ten independent examinations have to be made in order to detect dysplasia with $95 \%$ confidence (calculations performed by $\mathrm{Dr} O \mathrm{O}$ Kaalhus, Norsk Hydro's Institute for Cancer Research, Montebello, Oslo 3, Norway).

Nasal biopsies are of limited diagnostic value in individual cases for the same reasons, but they still appear to be valuable in identifying and monitoring groups occupationally exposed to nickel. From our experience with furniture makers (5) it seems probable that nasal biopsies may also prove valuable for the recognition of occupational hazards from other types of inhaled dust.

Further studies should be carried out to determine whether dysplasia is reversible or not. Irreversibility of dysplasia does not exclude the possibility of a regression of the premalignant state of the mucosa in that the dysplastic epithelium may gradually be replaced by the remaining nondysplastic normal epithelium. It is also impor- 
tant to evaluate whether the present level of nickel exposure is sufficiently low to prevent the occurrence of new cases of dysplasia.

Accumulating evidence from our present and previous morphological studies (3) supports the concept of nasal dysplasia as a precancerous lesion, particularly in view of the biological behavior of similar changes in other organs, eg, in the cervical and bronchial epithelium. However, further development of dysplasia into distinct malignancy appears to be a relatively rare event. Nevertheless, it should carefully be considered whether workers with such lesions should be transferred to other work. In any event, these workers should be followed closely for the early detection of nasal carcinoma.

\section{Acknowledgments}

This study was supported by the Norwegian Cancer Society.

The authors wish to thank Dr P Marton for his helpful discussions.

\section{References}

1. Andersen A, Høgetveit AC, Magnus K. A follow-up study among Norwegian nickel workers. In: Brown SS, Sunderman FW Jr, ed. Nickel toxicology. Academic Press, London 1980, pp 31-32.

2. Bernacki EJ, Sunderman FW Jr, MicacDevic M. Nickel excretion in urine of workers in nickel-plating and coal gasification operations. Ann clin lab sci 8 (1978) 184-189.

3. Boysen M, Puntervold R, Schüler B, Reith A. The value of scanning electron microscopic identification of surface alterations of nasal mucosa in nickel workers: A correlated light and scanning electron microscopic study. In: Brown SS, Sunderman FW Jr, ed. Nickel toxicology, Academic Press, London 1980, pp 39-42.

4. Boysen M, Reith $\mathrm{A}$. The surface structure of the human nasal mucosa: II Metaplasia, dysplasia and carcinoma in nickel workers: A correlated study by scanning/transmission and light microscopy. Virchows arch (cell pathol) 40 (1982) 295-309.

5. Boysen M, Solberg LA. Changes in the nasal mucosa of furniture workers: A pilot study. Scand $j$ work environ health 8 (1982) 273-282.

6. Doll R, Mathews JD, Morgan LG. Cancers of the lung and nasal sinuses in nickel workers. Br j ind med 34 (1977) 102-105.

7. Doll R, Morgan LG, Speizer FE. Cancer of the lung and nasal sinuses in nickel workers. $\mathrm{Br} \mathrm{j}$ cancer 24 (1970) 623-632.

8. Hogetveit AC, Barton RT. Preventive health program for nickel workers. J occup med 18 (1976) 805-808.

9. Høgetveit AC, Barton RT, Kostøl CO. Plasma nickel as a primary index of exposure to nickel refining. Ann occup hyg 21 (1978) $113-120$

10. International Agency for Research on Cancer. Nickel and nickel compounds. In: International Agency for Research on Cancer. Cadmium, nickel, some epoxides, miscellaneous industrial compounds and general considerations on volatile anaesthetics. Lyon, France 1976, p 75. (IARC monographs on the evaluation of the carcinogenic risk of chemicals to man, volume 11 ).

11. Mastromatteo E. Nickel: A review of its occupational health aspects. J occup med 9 (1967) 127-136.

12. McNeely MD, Nechay MW, Sunderman FW Jr. Measurements of nickel in urine as indices of environmental exposure to nickel. Clin chem 18 (1972) 992-995.

13. Pedersen E, Høgetveit AC, Andersen A. Cancer of the respiratory organs among workers at a nickel refinery in Norway. Int $\mathrm{j}$ cancer 12 (1973) 32-41.

14. Sunderman FW Jr. A review of the metabolism and toxicology of nickel. Ann clin lab sci 7 (1977) 377-398.

15. Sunderman FW Jr. Recent research on nickel carcinogenesis. Environ health perspect 40 (1981) $131-141$.

16. Torjussen W, Andersen I. Nickel concentrations in nasal mucosa, plasma, and urine in active and retired nickel workers. Ann clin lab sci 9 (1979) 289-298.

17. Torjussen W, Solberg LA, Hogetveit AC. Histopathological changes of nasal mucosa in nickel workers: A pilot study. Cancer 44 (1979) 963-974.

18. Torjussen W, Solberg LA, Hogetveit AC Histopathological changes of 'the nasal mucosa in active and retired nickel workers. Br j cancer 40 (1979) 568-579.

Received for publication: 9 August 1982 